\title{
General Psychiatry Cut it out or wait it out? Case series of middle fossa arachnoid cysts presenting with psychiatric symptoms and a discussion of the ethics of neurosurgical management
}

\author{
Petrus Johannes Steyn 두 , Leigh Luella Van den Heuvel
}

To cite: Steyn PJ, Van den Heuvel LL. Cut it out or wait it out? Case series of middle fossa arachnoid cysts presenting with psychiatric symptoms and a discussion of the ethics of neurosurgical management. General Psychiatry 2021;34:e100523. doi:10.1136/ gpsych-2021-100523

Received 16 March 2021 Accepted 27 October 2021
Check for updates

(C) Author(s) (or their employer(s)) 2021. Re-use permitted under CC BY-NC. No commercial re-use. See rights and permissions. Published by BMJ.

Psychiatry, Stellenbosch University Faculty of Medicine and Health Sciences, Cape Town, South Africa

Correspondence to Dr Petrus Johannes Steyn; steynp@sun.ac.za

\section{ABSTRACT}

Arachnoid cysts have been linked to neuropsychiatric morbidity. We describe two patients presenting with dissociative and manic symptoms believed to be associated with middle fossa arachnoid cysts. They were managed medically and remitted eventually, but symptoms were resistant. We briefly review the literature to discuss mechanisms by which cysts could cause symptoms and consider whether neurosurgical management would be appropriate. Although neurosurgery can be considered, its role is currently limited by practical and ethical considerations.

\section{INTRODUCTION}

Arachnoid cysts are benign space-occupying lesions mostly of the left temporal fossa. Although rarely caused by trauma, infection or neoplasia, they are usually developmental defects. ${ }^{1}$ These cysts represent $1 \%$ of intracranial masses and are commonly incidental findings. ${ }^{1-4}$ Most are asymptomatic, ${ }^{23}$ and vague symptoms might not be easily detected..$^{5} 6$ Neurosurgical management is mainly conservative. $^{13}$

The neuropsychiatry of arachnoid cysts is controversial (see table 1). Psychiatric illnesses exist in the case reports that either improved only after drainage of cysts ${ }^{4}$, or where drainage leads to a decreased need for medication $^{7}$ or where neurosurgical intervention was withheld and psychopathology proved resistant. ${ }^{8}$ Studies have found significantly more cognitive problems ${ }^{9}$ and pathological personality traits ${ }^{10}$ in patients with arachnoid cysts compared with normal populations.

There have also been studies that failed to show neuropsychological differences in patients with arachnoid cysts ${ }^{11}$ and case reports where psychiatric treatment, as usual, leads to predictable symptomatic improvement. ${ }^{3} \quad$ Improved understanding of the mechanisms by which cysts might contribute to symptoms is, therefore, necessary to aid decision-making.

We report two cases with middle cranial fossa arachnoid cysts with unusual clinical courses. We speculate whether the neurosurgical intervention could benefit our patients, considering the evidence for the cysts to be aetiologically significant, and discuss indications for surgery in these cases with special reference to ethical considerations.

\section{CASE HISTORY}

Case 1

A man in his early 20 s presented with aggression, hearing voices and poor sleep for 1 week. He had two previous involuntary psychiatric admissions and was diagnosed with schizophrenia. Prior to his first admission, social interaction and work performance deteriorated. He presented with positive symptoms, including auditory hallucinations.

He had no comorbidities or head injuries. He previously abused methaqualone and was still using cannabis regularly. Developmental and family histories were unremarkable. He functioned well until his first psychotic episode.

He had previously taken on olanzapine $15 \mathrm{mg}$ daily with flupenthixol depot $20 \mathrm{mg}$ per month but suffered extrapyramidal side effects on risperidone. He became nonadherent when visiting family in a rural district.

He was initially treated in a district hospital for a schizophrenia relapse with mood symptoms secondary to his cannabis use (urine positive for tetrahydrocannabinol). Several weeks after his admission, however, 


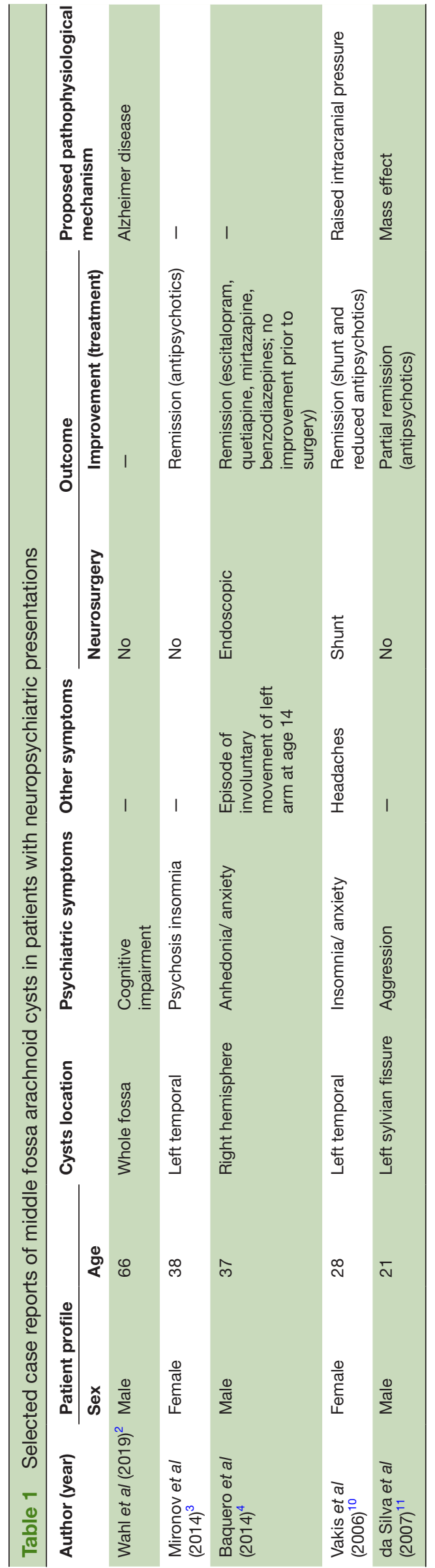

he displayed episodic mutism, posturing and urinary incontinence. He reported déjà vu and gustatory sensations preceding the symptoms but could not recall the episodes.

He was transferred to our unit for further work-up. His mental state at admission involved mood lability, rapid speech, tangential thoughts and grandiose delusions. Physical and neurological examinations, as well as special investigations, were normal. He had at least one further episode of déjà vu with altered behaviour in our unit.

CT of the brain showed a Galassi type 1 arachnoid cyst (42 $\mathrm{mm} \times 38 \mathrm{~mm} \times 39 \mathrm{~mm}$ ) in the left middle cranial fossa with a mass effect on the adjacent tissue. Electroencephalography (EEG) was normal. Neurosurgery suggested conservative management based on the Galassi classification of the lesion.

The patient was managed for the Diagnostic and Statistical Manual of Mental Disorders, 5th Edition (DSM 5) schizoaffective disorder, bipolar type, which proved to be resistant to treatment. He required sedation with clonazepam $6 \mathrm{mg}$ per day, which could only be weaned after 7 weeks on our ward. We increased olanzapine to $25 \mathrm{mg}$ daily and eventually added flupenthixol as long-acting injectable antipsychotic at $20 \mathrm{mg}$ monthly to augment this. Sodium valproate was added and increased to 1800 $\mathrm{mg}$ daily and he required the addition of lithium 750 $\mathrm{mg}$ daily (serum lithium $0.6 \mathrm{mmol} / \mathrm{L}$ ) before his symptoms abated. By the time of discharge, he was euthymic, psychosis resolved and he was not experiencing the episodes anymore.

\section{Case 2}

A man in his early 20s was admitted after a few days of irritability, grandiosity, insomnia and increased energy.

He first presented 2 years prior with periodical staring that started after the deaths of several family members. He reported derealisation. He made two suicide attempts but claimed no recollection of the entire episode, which resolved before he accessed medical care.

Work-up revealed a left anteromedial temporal arachnoid cyst measuring $46 \mathrm{~mm} \times 19 \mathrm{~mm} \times 28 \mathrm{~mm}$ with compressive effects on the left frontal and anteromedial left temporal pole on MRI. Two extended video EEG recordings of 74 hours and 19 hours showed no epileptiform activity. His neurologists felt temporal lobe epilepsy (TLE) was excluded. Two neurosurgeons recommended conservative management because of the absence of TLE.

He subsequently had four psychiatric admissions. Prior to each admission, there were 3 days of a stereotypical progression from blank staring, derealisation, talkativeness with increasing incoherence to mood lability and finally frank mania with misidentification delusions.

During previous admissions, he received trials of sodium valproate, lamotrigine, phenytoin and risperidone. His course was unpredictable. Episodes were eventually resolved, only to recur despite good adherence.

He had a minor head injury during adolescence for which no medical care was sought. He used nicotine only. 
He was born preterm as a result of a complicated twin pregnancy (the other twin stillborn). There was no family history of psychiatric illness.

During his latest admission, risperidone was increased to $4 \mathrm{mg}$ and sodium valproate was changed to lithium 500 mg owing to adverse effects. He responded rapidly and at his transfer to the care of a private psychiatrist in another city closer to his father's residence, he was euthymic, psychosis resolved and he displayed good insight. Lithium levels were not yet taken at the time of his transfer. Based on his atypical picture, we diagnosed him with DSM 5 bipolar and related disorder due to arachnoid cyst.

\section{DISCUSSION}

These cases highlight some of the practical diagnostic difficulties in patients with complex comorbidity. We considered the possibility of substance-induced bipolar and related disorder in case 1 but thought this less likely given the persistence of severe mood and psychotic symptoms over an abstinent period of longer than 2 months. This patient also had striking symptoms suggestive of temporal lobe dysfunction, which cannot be accounted for based on his psychiatric diagnosis alone. Similarly, in case 2, the bizarre presentation, reminiscent of TLE, in our opinion does not clearly fit any primary psychiatric syndrome.

It is impossible to know whether the arachnoid cysts were present before the first onset of psychiatric symptoms, but we believe they likely contributed to the clinical picture in both patients. In both cases, treatment resistance and the unpredictable course suggest that the cysts influence prognosis. This raises the question of whether surgery could change the course of illness. To answer this, we require reasonable confidence that the cysts could cause the symptoms and, secondly, that the risks of surgery do not outweigh the potential benefit.

Middle fossa arachnoid cysts have been associated with psychiatric symptoms. ${ }^{34}$ 7-10 Causality can be inferred by temporal lobe pathology in neuropsychiatric conditions, such as psychosis in relation to TLE. ${ }^{12}$ This is underlined by reports of the resolution of psychiatric symptoms following arachnoid cyst surgery. ${ }^{3}$

The mechanism is generally understood as a mass effect. It is not surprising that larger cysts more often require surgery. ${ }^{1}$ Reorganisation, hypoperfusion and hypometabolism occur in adjacent tissue, especially with higher intracystic pressures, and decompression might improve cerebral function in seemingly asymptomatic patients. ${ }^{167}$

However, most cysts enlarge slowly, if ever, allowing the tissue to adapt. ${ }^{13}$ The cranium is malleable in youth so that the presence of a cyst produces a larger intracranial volume without pressure effects. ${ }^{2}$ There is no linear association between cyst size and symptoms, or between neuroimaging improvement and symptom improvement postoperatively. ${ }^{5} 13$

An alternative pathological mechanism is neural network disruption. Non-mass effect symptoms of brain tumours are predicted by the networks they disrupt. ${ }^{14}$ The temporal lobes house rich club hubs of the human connectome. ${ }^{15}$ Strategic temporal lesions might, thus, disrupt the connectome and produce information processing inefficiencies, manifesting as psychiatric symptoms during stress. Not only the size of cysts but also individual connectivity patterns would predict symptoms. This could account for TLE-like symptoms without EEG evidence of temporal epilepsy in our patients.

There is, therefore, plausible evidence of middle fossa cysts causing neuropsychiatric symptoms and mechanisms to explain this. Some authors consequently argue that psychiatric symptoms constitute a surgical indication in their own right. ${ }^{4}$ Evidence for this is largely based on the case reports, with limited prospective research into the benefit of surgery. A small prospective study involving 22 patients, 18 of whom had temporal cysts, showed improvement on the Hospital Anxiety and Depression Scale following surgery, but the study lacked a control group. ${ }^{5}$

Surgery seems to be well tolerated. In a cross-sectional study of 149 patients who underwent surgery for arachnoid cysts, $66 \%$ had better overall functioning postoperatively, with few reported complications. ${ }^{6}$ A recent review stated that surgery for neuropsychological indications leads to greater improvement than surgery for certain other neurological indications. ${ }^{1}$

This suggests that surgery to alleviate psychiatric symptoms might be reasonable in some cases, although it is not clear who would benefit most. Unexpected changes in the clinical picture or a lack of response to treatment might warrant neuroimaging and, by extension, surgery. Nonetheless, the current evidence does not allow the finding of a cyst to be taken as clear evidence of causality in all cases.

The potential of surgery being a definite treatment, especially without evidence to predict when this expectation is realistic, currently raises an ethical dilemma of whether to advise surgery in individual cases. The hesitancy of neurosurgeons in our setting to intervene may indicate appropriate prudence, but could also stand in the way of significant improvement in morbidity for some patients.

Surgery could be an option in those selected patients who are informed of the weak evidence base, especially considering arachnoid cysts are both common and often benign. Issues of capacity and informed consent might further limit the role of surgery in acute psychiatry. The decision to operate should, therefore, be based on the consensus between the patient, psychiatrist and neurosurgeon. The involvement of the family, neuropsychologists, neurologists and ethicists could be prudent. If surgery is selected, anecdotal evidence from case reports suggests that minimally invasive procedures could be effective.

There are some major limitations to our study. First, this is a limited case series, and although it adds to a growing literature on the neuropsychiatry of arachnoid cysts, the ability to draw firm conclusions about the value 
of surgery is hampered by a lack of prospective studies with rigorous experimental design. Second, the lack of follow-up (which is a function of our hospital serving as a referral centre for several districts in a large province) limits our ability to comment on longer-term outcomes. Both patients returned to local psychiatric follow-up. Future prospective studies examining the natural progress of neuropsychiatric symptoms of patients with arachnoid cysts would be critical to improving our understanding of the appropriate management of these lesions.

Our study does, however, contribute to a growing literature on neuropsychiatric symptoms associated with middle fossa arachnoid cysts and adds impetus for further research into the nature of this relationship.

\section{CONCLUSION}

There is evidence that arachnoid cysts can cause neuropsychiatric symptoms and plausible mechanisms to understand how this occurs. The role of surgery is less clear. Until the evidence is more conclusive, ethical considerations might hinder its general use.

Contributors Both authors conceptualised the study and contributed to the literature review. PJS gathered clinical data and wrote the first draft of the article. Both authors contributed to editing the manuscript and finalising the article.

Funding The authors have not declared a specific grant for this research from any funding agency in the public, commercial or not-for-profit sectors.

Competing interests None declared.

Patient consent for publication Obtained.

Ethics approval Both patients provided written informed consent for this publication. Ethical approval was obtained from the Stellenbosch University Health Research Ethics Committee (HREC nr C20/09/029).

Provenance and peer review Not commissioned; externally peer reviewed.

Open access This is an open access article distributed in accordance with the Creative Commons Attribution Non Commercial (CC BY-NC 4.0) license, which permits others to distribute, remix, adapt, build upon this work non-commercially, and license their derivative works on different terms, provided the original work is properly cited, appropriate credit is given, any changes made indicated, and the use is non-commercial. See: http://creativecommons.org/licenses/by-nc/4.0/.

ORCID iD

Petrus Johannes Steyn http://orcid.org/0000-0002-4030-3060

\section{REFERENCES}

1 Mustansir F, Bashir S, Darbar A. Management of arachnoid cysts: a comprehensive review. Cureus 2018;10:e2458.

2 Wahl A-S, Löffler M, Hausner L, et al. Case report: a giant arachnoid cyst masking Alzheimer's disease. BMC Psychiatry 2019;19:274

3 Mironov A, John S, Auerbach J, et al. Acute onset of psychosis in a patient with a left temporal lobe arachnoid cyst. Case Rep Med 2014;2014:204025

4 Baquero GA, Molero P, Pla J, et al. A schizophrenia-like psychotic disorder secondary to an arachnoid cyst remitted with neurosurgical treatment of the cyst. Open Neuroimag J 2014;8:1-4.

5 Gjerde PB, Litleskare S, Lura NG, et al. Anxiety and depression in patients with intracranial arachnoid Cysts-A prospective study. World Neurosurg 2019;132:e645-53.

6 Helland CA, Wester K. A population based study of intracranial arachnoid cysts: clinical and neuroimaging outcomes following surgical cyst decompression in adults. J Neurol Neurosurg Psychiatry 2007;78:1129-35.

7 Park YS, Eom S, Shim K-W, et al. Neurocognitive and psychological profiles in pediatric arachnoid cyst. Childs Nerv Syst 2009;25:1071-6.

8 Lee S-H, Park Y-S, Nam T-K, et al. Psychopathological influence of middle fossa arachnoid cysts in young men: analysis of Korean conscription data. World Neurosurg 2019;122:e530-9.

$9 \mathrm{Kim} \mathrm{KH}$, Lee JY, Phi JH, et al. Neurocognitive profile in children with arachnoid cysts before and after surgical intervention. Childs Nerv Syst 2019;35:517-22.

10 Vakis AF, Koutentakis DI, Karabetsos DA, et al. Psychosis-like syndrome associated with intermittent intracranial hypertension caused by a large arachnoid cyst of the left temporal lobe. $\mathrm{Br} \mathrm{J}$ Neurosurg 2006;20:156-9.

11 da Silva JA, Alves A, Talina M, et al. Arachnoid cyst in a patient with psychosis: case report. Ann Gen Psychiatry 2007;6:16.

12 Kanner AM, Rivas-Grajales AM. Psychosis of epilepsy: a multifaceted neuropsychiatric disorder. CNS Spectr 2016;21:247-57.

13 Spansdahl T, Solheim O. Quality of life in adult patients with primary intracranial arachnoid cysts. Acta Neurochir 2007;149:1025-32.

14 Madhusoodanan S, Ting MB, Farah T, et al. Psychiatric aspects of brain tumors: a review. World J Psychiatry 2015;5:273-85.

15 Crossley NA, Mechelli A, Scott J, et al. The hubs of the human connectome are generally implicated in the anatomy of brain disorders. Brain 2014;137:2382-95.

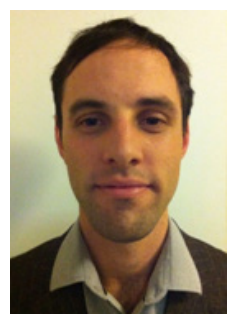

Dr Petrus Johannes Steyn is a third-year registrar (resident) in psychiatry at Stellenbosch University in Cape Town, South Africa, having joined the programme in August 2018. He obtained an MB, ChB degree from the same university in 2012 and also held a diploma in Mental Health from the College of Psychiatrists of South Africa. His main research interests include neuropsychiatry and biomarkers for psychiatric illness and he is also involved in research about the application of dialectical behaviour therapy in resource-limited African settings. 